\title{
Generalized Cash-Flow Taxation
}

\author{
Alan J. Auerbach \\ University of California, Berkeley, and NBER \\ David F. Bradford \\ Princeton University, NYU School of Law, NBER and CESifo
}

September 2002

Version cashflow.13

This paper was presented at the December 2001 ISPE conference on Income Taxation and Financial Innovation held in Berkeley. We are grateful to our discussants, Bob McDonald and Reed Shuldiner, as well as others at the conference for helpful comments. Thanks to Daniel Halperin, in particular, for pointing out problems related to changes in tax rates over time. We have also benefited from comments on earlier drafts by Ken Judd, Louis Kaplow, Jim Poterba and other participants in seminars at Cornell, Harvard, NYU, Princeton, Stanford and Texas, and two anonymous referees. 


\begin{abstract}
We show the unique form that must be taken by a tax system based entirely on realization accounting to implement a uniform capital income tax, or, equivalently, a uniform wealth tax. This system combines elements of an accrual based capital income tax and a traditional cashflow tax, having many of the attributes of the latter while still imposing a tax burden on marginal capital income. Like the traditional cash-flow tax, this system may be integrated with a tax on labor income. We also show how such a tax can be supplemented with an optional accounting for a segregated subset of actively traded securities, subjected separately to mark-to-market taxation at the uniform capital income tax rate, to permit a fully graduated tax system applicable to labor income.
\end{abstract}

Alan J. Auerbach

Department of Economics University of California Berkeley, CA 94720-3880

auerbach@econ.berkeley.edu
David F. Bradford

Woodrow Wilson School Princeton University Princeton, NJ 08544 bradford@princeton.edu

JEL Nos. H24, G11 


\section{Table of Contents}

1. Introduction 1

2. Generalized Cash-Flow Taxation 3

A. Derivation of the generalized cash-flow tax rule 3

B. Commentary 10

i. Intuition of the result 10

$\begin{array}{ll}\text { ii. Portfolio balance and risk-taking } & 11\end{array}$

iii. Portfolios and other combinations of assets 12

iv. Treatment of gains and losses $\quad 14$

v. Choice of parameters, $D$ and $g$

$\begin{array}{ll}\text { vi. Gifts and bequests } & 17\end{array}$

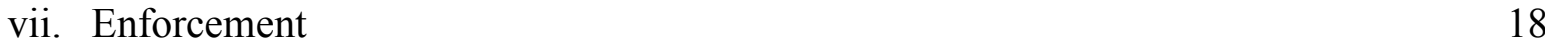

3. Extensions 20

A. Time-dependent capital income tax rate, wealth taxation, and inflation adjustment 20

i. Time-dependent capital income tax rate and wealth taxation 20

$\begin{array}{ll}\text { ii. Inflation adjustment } & 21\end{array}$

B. Closely-held assets and human capital accumulation 22

C. Lifetime progressivity and income averaging 24

D. Changing the tax parameters as a matter of changing policy 27

4. Conclusion 28

$\begin{array}{ll}\text { References } & 30\end{array}$

Appendix A. Basic Propositions 31

Appendix B. Intertemporal Optimization and Leisure 34 


\section{Introduction}

The growing flexibility of financial arrangements has wreaked havoc on the income tax. The problems arise in connection with the treatment of financial and business transactions generally lumped under the heading of "capital income." Transactions with similar economic effect face tax rules that differ with respect to the timing and the rate of taxation, essentially providing taxpayers with the opportunity to elect the most favorable tax treatment for any particular asset. This inconsistency also facilitates the construction of offsetting arbitrage positions that involve little net economic activity but that can be used to reduce tax liability on income from other, unrelated sources. The dysfunctional consequences appear in various guises, including the conversion of ordinary income into capital gains, the deferral of capital gains by individuals, and the recently publicized aggressive pursuit of tax shelters by corporations.

To date, policy responses have attempted to limit taxpayers' ability to engage in transactions, to throw sand in the gears of tax-motivated financial innovation. Such responses are inevitably imperfect, for there is no "correct" way to preserve a tax system that treats similar transactions inconsistently. Wherever the line is drawn to identify transactions with no economic substance, anti-abuse provisions may also catch taxpayers happening to choose a similar pattern of transactions. Ultimately, the problem will exist unless all types of income from capital are subject to the same present value tax burden, at least ex ante at the time decisions are made.

Directly imposing the same rate of tax on all income as it accrues requires a tax system that marks assets to market, a process that is straightforward for frequently traded assets but quite

\footnotetext{
${ }^{1}$ For the most part in this paper we implicitly invoke the traditional model, in which workers are paid a well-defined wage and separately accumulate claims on assets that have possibly stochastic payoffs in the future. In actuality, the rewards to work effort may have intertemporal (for example, deferred compensation) and risk elements (for example, stock options or share-cropping), and may be intertwined with accumulated capital (for example, in a business enterprise), so that an operational distinction between capital and labor income is problematic. In part 3 we show how the system proposed could be extended to all cash flows, thereby eliminating any need for a distinction.
} 
difficult for others. Indeed, with the rise in derivatives and synthetic assets, it is not even clear where to draw the boundaries separating one asset from another for purposes of valuing and taxing each. An alternative response is to ignore financial transactions entirely, or to impose a cash-flow tax on capital income. As various authors have shown, imposing a tax at a constant rate on all positive and negative cash flows still imposes a zero effective tax rate at the margin on the normal, risk-free return to capital income from new investment. But a shift to cash-flow taxation differs from elimination of capital income taxes with respect to timing and in taxing economic rents and, depending on transition rules, returns to existing assets as well. A frequently cited advantage of cash-flow taxation is that it can collect revenue from capital income sources (i.e., rents, such as the rewards to entrepreneurship and the supernormal return on investment, and, in the case of a transition from a different regime, old capital) without having to measure capital income. However, perhaps because it is poorly understood, or perhaps because policy makers are committed to the attempt to include the risk-free return to wealth in the tax base, the cash-flow tax has not been adopted as an alternative to the income tax.

In this paper, we show that it is possible to generalize cash-flow taxation in a manner that preserves this major advantage — not having to measure capital income — while at the same time effectively imposing an income tax at a constant rate on all capital income. This approach, to which we refer as generalized cash-flow taxation, resembles cash-flow taxation in that it taxes only cash flows and is not based on any measurement of income. However, unlike simple cashflow taxation, the tax assessment levied on any particular cash flow depends on that cash flow's date and the effective capital income tax rate that the government wishes to impose. As we show, such a tax system is equivalent, ex ante, from the viewpoint of both investor and government to a pure accrual tax at the same rate. It replaces the requirement of asset valuation 
(which may not be feasible) with the assumption that investors have the ability arbitrarily to adjust their risk positions. That is, our approach assumes the existence of a complete, competitive capital market in which price-taking investors can buy or sell assets in any quantities desired in order to adjust their portfolios to accommodate the timing of taxation. The impact of realistic deviations from these assumptions is a question that must be left for future research.

\section{Generalized Cash-Flow Taxation}

Our approach represents an extension of two previous papers, Auerbach (1991) and Bradford (1997), and may be most easily understood by starting with a brief review of these papers' results, using discrete time for clarity and mathematical simplicity. We start with the most basic of investor decisions, whether or not to sell (and therefore realize the income from) an asset with no intermediate cash flows between purchase and sale. The class of transactions considered initially consists of arm's length purchase, sale, and holding of financial assets traded in active public markets. Later we extend the scope of assets considered in several respects.

\section{A. Derivation of the generalized cash-flow tax rule}

Under a typical capital gains tax system with a constant tax rate, realization of a net gain is discouraged - the investor is "locked in"- because there is a deferral advantage to delaying, without interest, the taxation of gains. Put another way, the investor is willing to accept a lower before-tax rate of return on the asset than is available on other assets, because the tax on additional returns is effectively reduced by the eroded tax liability on gains already accrued.

This deferral advantage could be offset, and the additional returns on current and alternative assets subjected to uniform treatment, by charging (deductible) interest on unpaid 
taxes as gains accrued, as first envisioned by Vickrey (1939), with the tax liability at realization, $T$, evolving according to the expression

$$
T_{s+1}=[1+i(1-t)] T_{s}+t r_{s} A_{s},
$$

where $A_{s}$ is the value of the asset at date $s$ (with time measured from the acquisition date), $i$ is the safe rate of interest, $t$ is the income tax rate, and $r_{s}$ is the asset's rate of appreciation between dates $s$ and $s+1$. Unfortunately, implementation of the unique tax system based on (1) and the initial condition $T_{0}=0$ would require us to observe the path of $A_{s}$, i.e., the value of $r_{s}$, over time.

Following Auerbach (1991), we observe that Vickrey's approach is too restrictive if the objective is to eliminate the lock-in effect at each date $s$. Let $V(\cdot)$ be an operator that converts a date's uncertain returns into their certainty equivalents. ${ }^{2}$ As shown in Appendix A, the condition

$$
V\left(T_{s+1}\right)=[1+i(1-t)] T_{s}+t i A_{s},
$$

is necessary and sufficient for an asset held from date $s$ to date $s^{+1}$ to yield a before-tax return equal in certainty-equivalence to the before-tax interest rate. This is equivalent to the prospective gains on the asset facing an effective tax rate of $t$. Vickrey's system obeys (2), because in portfolio equilibrium the certainty-equivalent before-tax return on any risky asset equals the safe rate of return when assets are taxed uniformly, i.e., $V\left(r_{s}\right)=i$. But if we decompose the risky asset's return into two components, the safe return plus the excess return, then any tax system that imposes a tax rate $t$ on the safe return will satisfy (2). That is, a sufficient condition for (2) is that the tax liability, $T$, evolves according to

\footnotetext{
${ }^{2}$ One may think of this as applying state-contingent prices to uncertain returns in order to express them in units of a certain return.
} 


$$
T_{s+1}=[1+i(1-t)] T_{s}+t i A_{s}+t^{*}\left(r_{s}-i\right) A_{s}
$$

where $t^{*}$ is an arbitrary constant, because applying the operator $V(\cdot)$ to (3) eliminates the last term on the right-hand side of the expression. One can choose any value for $t^{*}$, and need not set $t^{*}=t$.

The underlying reason for this flexibility with respect to the choice of $t^{*}$ is that investors can offset changes in pure risk-sharing (i.e., variations in the tax rate on the excess return) with portfolio shifts between safe and risky assets (see, e.g., Sandmo 1985). Thus, an investor will not simply be indifferent, ex ante, with respect to the choice of $t^{*}$, but also in an equal position ex post, when the investor's entire portfolio is considered. Further, should the private sector's riskpooling be efficient, this variation in tax collections will also have no effect on the resulting equilibrium, once account is taken of the impact of the risk characteristics of government revenues (Gordon 1985, Konrad 1991, Kaplow 1994).

Replacing condition (1) with condition (3) does not directly indicate a solution to the problem of not being able to observe the path of $A_{s}$. However, a widened set of admissible tax structures might include some that do not require this information. Indeed, this turns out to be the case for one particular choice, $t^{*}=\left[1-\left(\frac{1+i(1-t)}{1+t}\right)^{s}\right]$, which results if $T$ is described by ${ }^{3}$ :

$$
T_{s}=\left[1-\left(\frac{1+i(1-t)}{1+i}\right)^{s}\right] A_{s}
$$

Under (4), the tax liability upon realization at date $s$ is independent not only of the evolution of $A$ over time, but also of the initial purchase price. The tax $T_{s}$ depends only on the amount realized,

\footnotetext{
${ }^{3}$ As period length declines, this expression approaches $T_{s}=\left(1-e^{-i t s}\right) A_{s}$, presented in Auerbach (1991).
} 
$A_{s}$, the realization date (and holding period) $s$, the safe interest rate, $i$, and the income tax rate, $t^{4}$ The liability in (4) is what would result if one assumed that the observed sale proceeds $A_{s}$ had resulted from accumulation at the safe rate from date 0 onward, and then imposed Vickrey's system on the assumed pattern of gains, starting with the imputed date- 0 value, $(1+i)^{-s} A_{s}$.

In Appendix A, we restate two other proofs based on the presentation in Auerbach. First, the expression in (4) is unique among tax regimes that (i) depend only on the same information set (notably, not on asset values at any other date) and (ii) impose no tax liability upon realizations at date 0 . Second, the final realization decision would still be undistorted by taxation for assets with intermediate distributions, if each distribution were also subject to taxation based on (4). This result will turn out to be important for our current investigation, because it paves the way for aggregating different assets under the same tax regime, not requiring that we identify the sources of distributions as long as they face a particular predetermined tax formula.

Bradford (1997) found that one could implement a more general tax system than the one described in (4) and yet still achieve holding-period neutrality. Considering again the simple case of an investment at date 0 with a realization at date $s$ and no intermediate cash flows, he proposed the following tax regime. Let $D$ be the gain reference date and $g$ be the gain tax rate. For the sake of intuition, imagine that $0 \leq D \leq s$, although this does not affect the algebra. What is crucial is that $D$ is fixed in advance of commitment to the cash flow sequence covered by the tax. The tax liability at date $s$ is computed in two steps. First, we calculate an imputed gain at date $D$, equal to the difference between the purchase price $A_{0}$, inflated at the safe rate of return to

\footnotetext{
${ }^{4}$ Expression (4) embodies the assumption that both the riskless interest rate and the capital income tax rate are constant. If they vary over time the tax rate corresponding to (4) is $T_{s}=\left[1-\prod_{\xi=0}^{s-1}\left(\frac{1+i_{\xi}\left(1-t_{\xi}\right)}{1+i_{\xi}}\right)\right] A_{s}$.
} 
date $D$, and the sale price at date $s$, discounted at the safe rate of return back to date $D$. We accumulate this date- $D$ liability to date $s$ at the after-tax interest rate:

$$
g\left[A_{s}(1+i)^{-(s-D)}-A_{0}(1+i)^{D}\right](1+i(1-t))^{(s-D)}
$$

Second, we compute tax at rate $t$ on all the imputed interest on the assumed accumulation from $A_{0}$ at date 0 to $A_{0}(1+i)^{D}$ at date $D$, plus all the imputed interest on the assumed accumulation from $A_{s}(1+i)^{-(s-D)}$ at date $D$ to $A_{s}$ at date $s$, and carry these liabilities forward at the after-tax interest rate to date $s$ :

$$
(1+i(1-t))^{(s-D)}\left[(1+i)^{D}-(1+i(1-t))^{D}\right] A_{0}+\left[(1+i)^{s-D}-(1+i(1-t))^{s-D}\right] A_{s}(1+i)^{-(s-D)}
$$

Combining these liabilities, the total tax under Bradford's system at date $s$ is:

$$
\left[1-(1-g)\left(\frac{1+i(1-t)}{1+i}\right)^{s-D}\right] A_{s}-(1+i(1-t))^{s}\left[1-(1-g)\left(\frac{1+i(1-t)}{1+i}\right)^{-D}\right] A_{0} \text {. }
$$

Figure 1 provides a graphical representation of this tax scheme, for an asset that appreciates from date 0 to date $s$ following the path shown by the thick line. The scheme uses only the initial and final asset values, $A_{0}$ and $A_{s}$, to generate two hypothetical projections of the asset value at date $\mathrm{D}$, each based on the interest rate, $i$ (see expression (5)). The difference between these hypothetical values is taxed at rate $g$, and the interest assumed to be earned until date $D$ and after date $D$ along the two hypothetical appreciation paths is taxed at rate $t$, with all tax liabilities determined at date $s$ and accumulated to that date. 


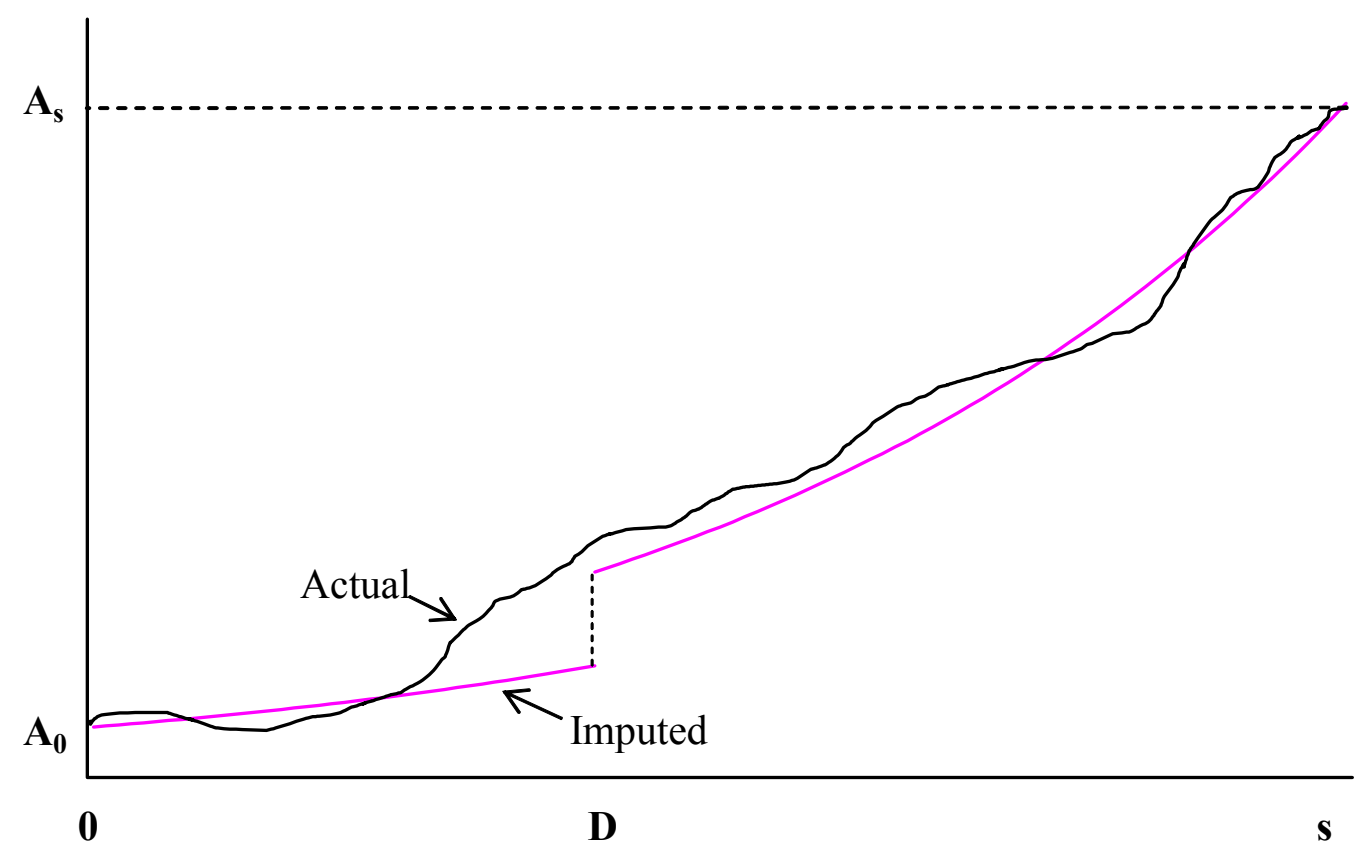

\section{Figure 1. Actual and Imputed Asset Value Trajectories under Bradford's Tax Scheme}

In relation to current tax rules, one may think of the second term in (7) as a reduction in tax liability reflecting the initial "basis" of the asset. In his original presentation, Bradford shows that the system in (7) leaves undistorted the realization decision for an asset on which the investor expects to earn the safe rate of return. He also notes that, for $D=g=0$, the system reduces to that outlined by Auerbach, given in (4) above.

Bradford's presentation envisions that all tax consequences are concentrated at the date of realization, $s$. In particular, it is necessary when applying (7) to take into account the asset's initial purchase price, $A_{0}$. Thus, the system would appear to impose greater informational requirements than that outlined by Auerbach. However, it is clear from inspection of (7) that the same economic impact would result from imposing separate taxes on the two cash flows associated with the project at their respective dates, $A_{0}$ at date 0 and $A_{s}$ at date $s$. That is, one 
could impose a cash-flow tax at rate $\left[1-(1-g)\left(\frac{1+i(1-t)}{1+i}\right)^{s-D}\right]$ on the sale at date $s$ and a cashflow tax at rate $\left[1-(1-g)\left(\frac{1+i(1-t)}{1+i}\right)^{-D}\right]$ on the initial purchase (i.e., provide a deduction at that rate) at date 0 , which has the same present value as the deduction of $(1+i(1-t))^{s}\left[1-(1-g)\left(\frac{1+i(1-t)}{1+i}\right)^{-D}\right] A_{0}$ at date $s$. The advantage in imposing the tax separately with respect to each cash flow is that each one may then be treated without reference to the other. It follows intuitively that, just as in Auerbach's system, the tax system would continue to work with intermediate cash flows, with each flow being subject to the same tax formula as the initial and final cash flows. Indeed, this is shown in Appendix A.

We refer to this modified version of Bradford's approach, taxing each date- $v$ cash flow (positive and negative) from an asset at rate $\left[1-(1-g)\left(\frac{1+i(1-t)}{1+i}\right)^{v-D}\right]$, as generalized cashflow taxation. Like cash-flow taxation, it imposes a tax on each cash flow without reference to the asset's value or cash flows at other dates. Unlike a standard cash-flow tax, though, which would result at rate $g$ by setting the income tax rate $t=0$, the generalized cash-flow tax effectively imposes a tax at rate $t$ on accruing capital income.

Given that the tax liability at date $s$ depends only on the same information set as Auerbach's system, one may be led to question Auerbach's proof of uniqueness for his approach. Note, though, that the tax liability associated with the asset sale under the generalized cash-flow tax is not zero for a realization at date 0 , as assumed in Auerbach's proof of uniqueness. Rather, there may be a positive (or negative) tax on sale proceeds, even for an asset sold at the same time 
as it is purchased. For example, if the gain reference date $D=0$, then a sale at date 0 generates a tax liability of $g A_{0}$. Note, though, that a purchase at the same date would generate a deduction of $A_{0}$ at rate $g$, resulting in a net tax liability of zero. The result is identical to Auerbach's in this case, in which the asset is purchased and sold at the same time. However, the net tax liability would not necessarily equal zero if the taxpayer acquired the asset by means other than a market purchase, a distinction that will prove important.

Relaxing the restriction of a zero-tax liability at date 0 , the system of generalized cashflow taxation is unique given its informational requirements. This, too, is shown in Appendix A.

\section{B. Commentary}

\section{i. Intuition of the result}

It is well known that the "zero" tax on a zero net present value investment that is characteristic of the conventional cash-flow tax fails when the tax rate applied is varying over time. A declining cash-flow tax rate has the effect of encouraging current deductible investment, while a rising tax rate discourages it. A tax rate rising at just the right rate in a conventional cash-flow tax will reproduce the effect of an accrual income tax as far as the opportunities presented to and hence the incentives of the investor are concerned. Specifically, if the fraction of a cash flow that the investor gets to keep (or has to give up, in the case of an outflow) is falling at a rate equal to some fraction of the interest rate, then the tax has the same impact as an income tax at that same fractional rate.

To spell this out, note that, with an income tax, an investment of 1 today would generate $1+(1-t) i$ in a year. With a cash-flow tax at rate $f_{v}$ at the current date $v$, one could invest $\frac{1}{1-f_{v}}$, taking into account the rebate due to the cash-flow tax. A return at interest rate $i$ implies 
a payoff of $\frac{1-f_{v+1}}{1-f_{v}}(1+i)$, net of cash-flow tax, in a year. The net return to the taxpayer who invests 1 at date $v$ will be $1+(1-t) i$, that is the cash-flow tax will mimic the income tax, if the fraction retained, $1-f_{v}$, evolves according to $\frac{1-f_{v+1}}{1-f_{v}}=\frac{1+(1-t) i}{(1+i)}$. In the generalized cash-flow tax, the fraction of a cash flow that the investor gets to keep at date $v$ is $(1-g)\left(\frac{1+i(1-t)}{1+i}\right)^{v-D}$. The ratio of this fraction at a given time to its value a year earlier is $\frac{1+(1-t) i}{(1+i)}$, exactly fulfilling the requirement to simulate an accrual tax at rate $t$.

\section{ii. Portfolio balance and risk-taking}

As with Auerbach's original scheme, the generalized cash-flow tax effectively imposes a tax at rate $t$ on the safe return, $i$, but a different tax rate on the excess return, $r_{s}-i$ at date $s$. It is straightforward to show that this tax rate is $t_{s}^{*}=\left[1-(1-g)\left(\frac{1+i(1-t)}{1+i}\right)^{s+1-D}\right]$. An investor in a risky asset seeking to undo the impact of taxation on risk taking would then need to increase the holding of the risky asset not by the factor $1 /(1-t)$, as would be the case under a standard income tax, but by the factor $1 /\left(1-t_{s}^{*}\right)$, or $\left[(1-g)\left(\frac{1+i(1-t)}{1+i}\right)^{s+1-D}\right]^{-1}$. For the special case of a simple cash-flow tax $(t=0)$, the response would increase the risky asset holding by the factor 1/(1-g), a well-known result. More generally, the investor would need to hold an increasing share of the risky asset over time. This conclusion presumes, however, no change in the "background" risk imposed on the investor by government policy. As discussed above in relation to the literature on taxation and risk taking, if markets for risk sharing are efficient, then 
the increasing risk of government revenue will undo the risk-reducing aspect of taxation on aggregate investment in risky assets. Still, each individual's share of the risky asset would need to grow over time to offset the risk-reducing impact of taxation, unless the government's allocation of tax revenue risk among individuals grew sufficiently with age to counter the direct impact of taxation. That is, with tax rates rising with age, the individual would normally have to take on more and more before-tax risk to deliver the same after-tax risk. Only if the government's allocation of risk rose fast enough with age would such increased risk-taking through portfolio decisions be unnecessary.

\section{iii. Portfolios and other combinations of assets}

Because the generalized cash-flow tax may be applied to any asset, regardless of its cash flows, its properties are preserved if it is imposed on any combination of assets, as long as the same tax parameters $(i, t, D$, and $g$ ) apply. That is, if we choose two assets in an investor's portfolio and apply the same generalized cash-flow tax to each, the outcome is identical to aggregating the two assets and then applying the generalized cash-flow tax with the same parameters to the combined cash flows of the two assets. Similarly, should the investor break a single asset into pieces, this will have no tax consequences. This invariance leads to an important conclusion: the system not only imposes an income tax rate $t$ on the returns to any particular investment, but will do so regardless of how the investment is characterized by the investor or, indeed, even whether the investment's existence is acknowledged.

Example 1: Consider the put-call parity theorem of finance, which establishes the equivalence between an equity position combined with a put option and a call option at the same strike price, and a safe zero-coupon bond with a single payment equal to that strike price. Both positions convey a risk-free return; the bond does so directly, while the equity position is perfectly hedged 
by the investor's ability to dispose of the asset if its value falls below the strike price (by exercising the put option) and the investor's being required to relinquish the asset if its value rises above the strike price (through the exercise of the call option by its purchaser). Under current law, these two equivalent positions face different tax treatment; the bond would be taxed over time subject to the original issue discount rules, while the equity and options would not. However, under a generalized cash-flow tax, the combined cash flows of these two positions would be identical and so, therefore, would be their pattern of tax payments.

Example 2: A problem under current tax rules is when to combine two sides of a hedging transaction. If one asset is a mirror image of another, logic and practice suggest that they should be combined for tax purposes to avoid a pure arbitrage transaction. But one position may hedge a combination of several other positions, no one of which is a close match to the first position by itself. Such "portfolio" hedging is typically ignored by tax rules, but offers the same arbitrage potential as the simple hedge. Both sets of positions would be automatically merged under generalized cash-flow taxation, without any action required on the part of tax authorities.

Example 3: Some assets may not even be identifiable until they begin generating cash flows. This may be especially the case for closely held assets. We take up below the extension of the generalized cash-flow tax beyond arm's length financial assets. The flavor of that extension is suggested by the example of a firm or individual possessing the knowledge required to develop a certain technology. This knowledge has value, and the value of this asset will change over time. Generalized cash-flow taxation will effectively impose an income tax on these changes in value, through its anticipated impact on future cash flows. This implicit taxation of accruing gains will also make the tax system neutral with respect to the investor's decision regarding when to "reveal" the asset's existence by implementing the associated technology in production. 


\section{iv. Treatment of gains and losses}

The Auerbach rule results in what may seem, at first sight, to be an odd treatment of gains and losses; to wit, a gain, in itself, gives rise to no extra tax and a loss to no reduction in tax. The sale value of the asset with no intermediate distributions is, in effect, treated as the result of accumulation at the safe interest rate since the date of acquisition. No extra tax is due if, in fact, the asset has jumped in value since that date; no allowance is given if, in fact, the asset has lost value. As emphasized by both Auerbach and Bradford, there is nothing wrong with this feature of the rule applied to transactions at arm's length in a capital market that permits costless construction of all zero-value "bets." Gains or losses relative to accumulation at the risk-free interest rate are the results of good or bad outcomes of such bets. Any rate of tax applied to a bet has the effect of reducing its scale but not its essential stochastic character. (This statement will not hold if the tax rate depends on the size of the gain or loss, as it may in a graduated-rate system.) As a result, any tax applied to bets can be completely offset, at the discretion of the investor/gambler, simply by changing the scale of a zero-value bet in the financial markets.

As described in the exposition of the concept, the generalized cash-flow tax has the effect of subjecting to tax, at rate $g$, gains and losses, relative to the risk-free results, all brought by appropriate back or forward discounting to gain reference date, $D$. We suggest below that this feature of the generalized cash flow rule may have a useful practical role to play. As long as we are dealing with arm's length transactions in a dense capital market, however, the investor is theoretically indifferent to the gain tax, since it can be completely offset with zero-value bets.

\section{v. Choice of parameters, $D$ and $g$}

The original Bradford scheme conceived of setting (perhaps by free choice of the investor) the "capital gain" parameters, $g$ and $D$, that would apply to each asset in isolation; $D$ 
was described as a time since the acquisition date of the asset. So long as there is no ambiguity about the identity of an asset (so that, in particular, its acquisition date is well defined), it is conceptually permissible for each asset to have its own values of $D$ and $g$. As has been suggested above, the identity of assets in this sense is, however, problematic when one takes into account transactions such as mergers and sale of some rights pertaining to an asset. These problems vanish when the same values of $D$ and $g$ apply to all assets, where $D$ now has the interpretation of a particular calendar date, rather than a time since acquisition.

Conceivably, one could specify such common values to apply to all investors at all times. The implication would be a rate of taxation of gains and losses that tends over time toward 100 per cent (reminder: the tax rate at time $v$ is given by $\left[1-(1-g)\left(\frac{1+i(1-t)}{1+i}\right)^{v-D}\right]$. As a theoretical matter this is no problem, so long as we confine our attention to arm's length investment choices, where only intertemporal and risk allocations are involved. If investors want to take a particular risk position, they can do so, independently of the tax applicable to gains and losses, by taking appropriate zero-value hedging positions. As a practical matter, however, one can imagine some problems with an investor getting a tax rebate of 99.9 percent of the amount invested, and paying 99.93 percent on the return flow in a few years' time. Among other problems, this would require the investor to take a huge position in the risky asset to offset the nearly complete absorption of risk by the government.

A way around this practical problem would be to specify separate pairs of values of $g$ and $D$ for each taxpayer. (Throughout we assume taxpayers are natural people, not companies.) Suppose, for example, $D$ were chosen to be either the taxpayer's date of birth or $40^{\text {th }}$ birthday. 


\begin{tabular}{|c|c|c|c|c|c|c|c|c|c|c|c|c|c|c|}
\hline & \multicolumn{14}{|c|}{ Age (in Years) at Gain Reference Date (D) } \\
\hline & \multicolumn{7}{|c|}{$\mathbf{0}$} & \multicolumn{7}{|c|}{40} \\
\hline \multirow[b]{2}{*}{ Age } & \multicolumn{14}{|c|}{ Gain Tax Rate (g) } \\
\hline & 0.0 & 0.1 & 0.2 & 0.3 & 0.4 & 0.5 & 0.6 & 0.0 & 0.1 & 0.2 & 0.3 & 0.4 & 0.5 & 0.6 \\
\hline $\mathbf{0}$ & 0.0 & 10.0 & 20.0 & 30.0 & 40.0 & 50.0 & 60.0 & -22.1 & -9.9 & 2.3 & 14.5 & 26.7 & 38.9 & 51.1 \\
\hline 20 & 9.5 & 18.6 & 27.6 & 36.7 & 45.7 & 54.8 & 63.8 & -10.5 & 0.5 & 11.6 & 22.6 & 33.7 & 44.7 & 55.8 \\
\hline 40 & 18.1 & 26.3 & 34.5 & 42.7 & 50.9 & 59.1 & 67.3 & 0.0 & 10.0 & 20.0 & 30.0 & 40.0 & 50.0 & 60.0 \\
\hline 60 & 25.9 & 33.3 & 40.7 & 48.1 & 55.6 & 63.0 & 70.4 & 9.5 & 18.6 & 27.6 & 36.7 & 45.7 & 54.8 & 63.8 \\
\hline 80 & 33.0 & 39.7 & 46.4 & 53.1 & 59.8 & 66.5 & 73.2 & 18.1 & 26.3 & 34.5 & 42.7 & 50.9 & 59.1 & 67.3 \\
\hline
\end{tabular}

Assumes interest rate $(i)$ of 2 percent and capital income tax rate $(t)$ of 25 percent.

\section{Table 1. Generalized Cash-Flow Tax Rates (in percent) at Various Ages for Gain Reference Date, $D$, Equals 0 or 40 and Various Gain Tax Rates, $g$}

Table 1 displays the tax rates that would apply at various ages for various choices of gain tax rates, $g$, assuming a risk-free interest rate of 2 percent and capital income tax rate of 25 percent. (A negative entry means that the taxpayer gets a subsidy upon a positive realization and pays a tax upon making an investment.) For the $(D, g)$ combination $(40, .3)$, for example, a 40 year-old would face a tax rate of 30.0 percent. That same individual would face a tax rate of 36.7 percent 20 years later, at age 60 , the rising cash-flow tax rate simulating the effect of an income tax. All of these age-tax rate structures are identical in their effect on intertemporal choice. In particular, applied to any given portfolio they generate the same value of tax revenue, discounted at the after tax rate of return. The age-tax rate structure in the Auerbach scheme, with its implicit gain tax rate of zero, is shown in the first column of each panel.

As illustrated, the tax rate increases with $g$ and decreases in $D$. Although the variables $g$ and $D$ each have an intuitive definition, any given schedule can be replicated by an infinite combination of values of $g$ and $D$. In our basic case of constant riskless interest and capital 
income tax rates, such combinations satisfy the equation $(1-g)\left(\frac{1+i(1-t)}{1+i}\right)^{-D}=x$ for some value of $x$. This result has a useful application if the future interest rate or capital income tax rate are uncertain. If the date $D$ is in the future, the generalized cash-flow tax rate applicable in the current period depends on those future rates. By choosing instead a lower value of $D$ (for example, 0 ) and a correspondingly higher value of $g$, one obtains a system that is based on currently or historically observed interest rates only. (The flexibility to choose $D$ and $g$ is reduced if the system is extended to labor income, as also discussed below.)

\section{vi. Gifts and bequests}

Where the tax parameters are specific to the taxpayer a new issue arises: the treatment of transfers between taxpayers. Important examples would include transfers between spouses and between parents and children. The subject of interspousal transfers would take us on too long an excursion into the treatment of married versus unmarried couples for adequate discussion here. With respect to the treatment of intergenerational transfers, the discussion in the U.S. Treasury's Blueprints for Tax Reform (Bradford et al., 1984; hereinafter Blueprints) of the same problem in the framework of that study's cash-flow tax may be relevant. A way to think about the transfer issue is whether amounts given away should seen as "consumed" by the giver, or not. There seems to be no particularly compelling a priori theoretical answer to this question. Blueprints favored excluding gifts from the tax base of the giver and including them in the tax base of the recipient. This approach has an administrative advantage in that in the typical case (in which the asset is not disposed of) there are no tax consequences at the time of transfer of an asset. ${ }^{5}$

\footnotetext{
${ }^{5}$ We can think of such a transfer as involving an implicit sale, taxed to the transferor, a gift, deducted by the transferor, taxable receipt by the transferee, and deductible saving by the transferee.
} 
Following this approach under the generalized cash-flow tax would present no problem in the "universal $D$ " case but would pose administrative challenges in the system involving a separate $D$ for each individual. In this world it would probably be necessary to treat a gift or bequest as a realization event for the transferor (presumably with no deduction by the transferor and no inclusion of amounts received in the tax base of the transferee). This requirement would present an arguably minor breech in the strict cash-flow accounting involved in the scheme, a breech tempered to the extent that valuation is required for transfer tax purposes in any event. ${ }^{6}$

\section{vii. Enforcement}

Both the Auerbach and Bradford concepts were motivated by interest in the possibility of taxing consistently the yield from assets that could and could not be readily marked to market. The former yields were assumed taxed on an accrual basis, whereas taxation of the latter had inevitably to be on what Warren (1993) calls a "wait and see" basis. The presumption was that some assets are taxed on an accrual basis, which translates in the models as a tax on the basis of the observed interest rate. The alternative modified taxation of realized cash amounts, developed here as generalized cash-flow taxation, was thought of as the treatment that would hypothetically be imposed on assets for which accrual taxation was impractical, much as realization accounting is done in the existing income tax.

Our current analysis has emphasized an additional benefit to generalized cash-flow taxation that obtains from subjecting all investment or capital income cash flows to the same tax system, namely elimination of the opportunity to take advantage of differences in tax treatment.

\footnotetext{
${ }^{6}$ An alternative approach would be to maintain the donor's $D$ even after the transfer and not treat the gift as a realization event, which parallels the existing treatment of gifts of appreciated assets, which are not realization events and for which the donor's basis is transferred to the recipient. While this approach has the advantage of avoiding realization and a change in the asset's tax attributes, it would require recipients to maintain separate accounts with different values of $D$, even after the disposition of the assets initially transferred.
} 
However, if the new tax system is to be applied only on a limited basis, this raises the question of how one distinguishes the cash flows to which the modified cash-flow tax applies from those associated with transactions subject to accrual accounting.

One possibility would be to use a device analogous to the Qualified Accounts suggested in the Blueprints cash-flow tax. In the Blueprints cash-flow tax, in which a zero rate of tax on capital income is the objective, the default treatment of financial flows involving arm's length assets is to ignore them. Net flows from a Qualified Account are, by contrast, included in the cash-flow tax base (so net deposits are deducted). In the context of the generalized cash-flow tax on capital income, the default would be to subject all "capital income associated" cash flows to the proposed time-varying rates, with deduction in the case of negative flows. ${ }^{7}$ A taxpayer that wanted to elect the present style treatment of capital income would have access to a "Tax Anticipation Account." Net flows from a Tax Anticipation Account, limited to assets traded on active security markets, would be excluded from the generalized cash-flow tax base. That means the investor would get no deduction for a deposit and pay no tax on a withdrawal. Instead, the Tax Anticipation Account would be subjected to tax on a mark-to-market basis at the appropriate capital income tax rate. It is important to stress here that eligibility for the Tax Anticipation Account must be limited to assets held at arm's length. Otherwise, the taxpayer could arbitrage the differences in tax treatment by constructing assets with below-market returns to be taxed on an ex post basis and assets with above-market returns to be taxed on an ex ante basis.

\footnotetext{
${ }^{7}$ At this point we are assuming individual investment flows are distinguishable from "labor income" flows; we take up below the problem of making such distinctions.
} 


\section{Extensions}

A. Time-dependent capital income tax rate, wealth taxation, and inflation adjustment

\section{i. Time-dependent capital income tax rate and wealth taxation}

Our derivation of the generalized cash-flow tax shows how it is possible to duplicate in essential economic effects a capital income tax imposed at some specified rate on accruing income. We have mentioned how the Auerbach tax can be adjusted for time-varying riskless interest and capital income tax rates. In the generalized cash-flow tax, the corresponding refinement of the tax rate would be $\left[1-(1-g) \prod_{\xi=D}^{v}\left(\frac{1+i_{\xi}\left(1-t_{\xi}\right)}{1+i_{\xi}}\right)\right] A_{v}$.

When the riskless interest and capital income tax rates are stochastic, we need to consider how to deal with the generalized cash-flow taxation of receipts and outlays occurring before the date $D$ in the formula. One possibility, contemplated in Bradford's scheme, would be to postpone resolving the tax liability until the arrival of $D$, with appropriate discounting of tax implications to the time of tax payment. The other option, mentioned earlier, would be to choose a value of $D$ that would always be in the past for the affected investor. A more significant issue, to which we return below, is the possibility that the gains tax rate, $g$, will change in the future.

By subjecting all capital income cash flows to the generalized cash-flow tax, one could implicitly impose any tax rate trajectory, unconstrained by arbitrage conditions with respect to assets subject to accrual taxation. In particular, one could simulate any desired capital income tax rate trajectory. Think of the generalized cash-flow tax rate as obeying $\left[1-(1-g) \gamma^{s-D}\right]$, where $\gamma$ is a parameter to be chosen as a matter of policy. If we choose $\gamma=\left(\frac{1+i(1-t)}{1+i}\right)$, where $i$ and $t$ have the standard interpretations, we produce the effect of an accrual tax at rate $t$ on 
the actual interest rate, $i$. But we could choose the parameter $\gamma$ directly. This will be equivalent to an effective capital income tax on nominal capital income at rate $t=\frac{(1+i)(1-\gamma)}{i}$. One may also view the result as equivalent to a uniform wealth tax (applied each period to the amount carried into the next period) at rate $(1-\gamma)$. Under this inclusive approach, one need not observe the risk-free interest rate to implement a tax system with a single effective rate of tax on all capital income. Only the parameter $\gamma$ need be specified, although the effective rate of capital income tax will depend on the actual value of the interest rate. The requirement that all capital income cash flows be covered is important. If the taxpayer had the alternative of electing accrual income taxation, there would generally be an inconsistency between the two (unless the capital income tax rate actually were set at $\left.t=\frac{(1+i)(1-\gamma)}{i}\right)$.

\section{ii. Inflation adjustment}

As emphasized by Bradford (1997), the capital income tax effected by the generalized cash-flow tax is certainly not "correct" if taxation of real capital income is the objective. With a positive rate of inflation, taxing nominal interest income at a constant rate would imply taxing real interest income at a higher, perhaps time-varying rate. The previous discussion relating to wealth taxation indicates that it would be conceptually easy to use the generalized cash-flow tax to impose an inflation-corrected capital income tax: if $i^{*}$ is the real interest rate, then one would substitute $i^{*}$ for $i$ in determining $\gamma=\left(\frac{1+i(1-t)}{1+i}\right)$, the generalized cash-flow tax formula. 


\section{B. Closely-held assets and human capital accumulation}

As discussed in Auerbach (1991), the original approach to retrospective taxation of individual assets encounters problems when assets are closely held; in particular, the system yields the wrong result when investors can misrepresent the return stream and cost associated with a particular asset. As already discussed here, this problem is overcome to the extent that alternative assets are also included under the proposed tax regime, for then the tax calculation aggregates all cash flows, regardless of the asset with which they are associated by the investor. But a key borderline remains between labor and capital income.

If an investor has the choice of purchasing an asset or constructing it himself through his own effort (think of a venture capital operation), the choice should not be distorted by taxation. Yet a distortion will exist if the proposed system applies only to capital income. Under the

Auerbach scheme, for example, the individual would avoid tax on imputed labor income used to produce a self-constructed asset, but would be taxable on labor income used to finance the asset's market purchase. Even under the generalized scheme, the distortion will remain unless the labor income tax and the generalized cash-flow tax are equal at each date, in which case the investor's decision to report imputed labor income would have no tax consequences, the extra tax being exactly offset by the extra cash-flow deduction associated with the asset purchase.

Two policy responses suggest themselves. On the one hand, perhaps taxing labor income at rates rising over time is undesirable and the inclusion of labor income under the generalized cash-flow system unnecessary. For individuals facing only the classic labor-leisure decision, the level and pattern of labor tax rates over time should be determined by the distortions associated with this decision. Even in this case, the rising tax schedule might make sense. As shown in Appendix B, the household's intertemporal marginal rate of substitution for leisure under this 
regime will be based on the before-tax interest rate, as would be true in the absence of taxation. It is not clear that a zero intertemporal labor distortion is optimal in this second-best world, in which the intertemporal consumption and labor-leisure distortions remain. But considering the optimality of intertemporal labor taxation raises the broader question of how the income tax rate $t$ is determined in the first place. This issue is important but lies beyond the scope of this paper.

Where the definition of labor is unclear, a common tax rate for labor and capital is an administrative advantage. Another attractive feature of the system of rising tax rates is that, if individuals make decisions about human capital investment, such investments would not longer be favored by the tax system as they are in a conventional income tax. The rising rates would eliminate the relative tax benefit given human capital (or other) investment that is financed with foregone earnings when labor income tax rates are constant over time. To see this intuitively, note that such investment receives its favorable treatment because imputed labor income that is foregone when such an investment occurs is not subject to taxation. If individuals were forced to report such imputed income and receive basis in the capital investment, the tax advantage would go away (assuming economic depreciation for all investments). The proposed inclusion of labor income under the generalized cash-flow tax would eliminate the net tax consequences of deciding to report such imputed income and an asset purchase of equal size. Human capital investment would be treated no better or worse than other investments, a point made in a related context by Kaplow (1996). Human capital is just another instance of a self-constructed physical asset, the only potential difference being in how the future income is characterized. With all cash flows being taxed at the same rate regardless of being categorized as "labor income" or "capital income" the treatments of self-constructed physical assets and human capital are identical to each other and to the treatment of purchased assets. 
Indeed, this effect of rising labor income taxes over time has been submitted as a defense of the Nordic approach to dual income taxation, which imposes a proportional tax on capital income but a progressive tax (typically inducing rising marginal tax rates over the productive part of the life cycle) on labor income (Nielsen and Sørensen 1997).

\section{Lifetime progressivity and income averaging}

Once the capital income tax rate has been set, the properties of the tax on earnings at different ages are determined by the " $D$ and $g$ " combinations.

Table 1 gives a sense for the pattern of tax rates at various ages implied by typical choices. Although the tax rates vary over the life cycle, they do not vary with the level of lifetime income. A natural question is whether one could, alternatively, apply some sort of graduated rate structure to cash flows in order to achieve progressivity in the system. The difficulty is that, if earnings or cash flows are not uniform over time, a graduated rate structure will generate intertemporal variation in the rates that will upset the uniform capital income taxation aimed for by the system.

A similar problem confronted the Blueprints cash-flow tax. In that case, where a zero rate of capital income taxation was an objective, the aim was to assure that a taxpayer would always confront the same marginal rate on cash flows, thereby eliminating the inefficiency that would result from a time-varying rate of tax and effecting a tax burden based on an arguably appropriate average of lifetime consumption. Because of variation in consumption over time (and the fact that some assets, notably owner-occupied houses, were excluded from the system), this would be an unlikely result if a graduated rate structure were strictly applied to all cash flows. Instead, under the Blueprints cash-flow tax, the taxpayer is given the option to choose between two forms of accounting for cash flows associated with arm's length investing. Net 
deposits to a Qualified Account are deducted from the tax base; other "nonqualified" investment and disinvestment transactions in arm's length financial assets are ignored by the system. A nonqualified investment sacrifices the benefit of deduction for up-front outflows from the taxpayer, but the return is free of tax.

Under this approach, a taxpayer anticipating a rising cash-flow tax rate would find it advantageous to remove funds from Qualified Accounts (adding to the current tax base, thereby inducing a higher current marginal tax rate) and invest them in nonqualified form (reducing the future tax base, thereby inducing a lower future marginal tax rate). Such a transaction would add to the current tax base and reduce the future tax base by the same amount in present value. The result would be a reduction in the discounted lifetime tax flow (because the marginal tax rate is lower in the present than in the future). Continuing this process, the taxpayer would seek to maintain a constant anticipated marginal tax rate. For taxpayers with higher lifetime inflows, for example owing to high labor earnings, the marginal tax rate that would result from such (desirable) tax planning would be higher than for taxpayers with lower lifetime inflows.

In the framework of the generalized cash-flow tax, the Tax Anticipation Account could be deployed to similar effect. Net deposits to the Tax Anticipation Account, subject to accrual income taxation, would be excluded from the generalized cash-flow tax base. The generalized cash-flow tax would be determined by applying to included cash flows a graduated rate structure, derived from a conventional graduated rate structure by making it age dependent in such a way that the marginal net of tax rate at each tax base level declines at the after-tax interest rate.

A potential complication of this approach to averaging is that it depends on the taxpayer's ability to allocate assets across the two types of accounts. As stressed above, this opens up the possibility of tax arbitrage unless the taxpayer's allocation decision is constrained to assets held 
at arm's length. But successful averaging would still be possible. For example, it could be accommodated even if the taxpayer's choice were restricted to government bonds specially created for this purpose. The government could permit each individual to establish a pair of special government bond accounts, the balances of which would be updated on the taxpayer's annual tax return. One account would be subject to generalized cash-flow taxation, the other to accrual taxation. The two accounts would carry the same rate of interest, and the balance in either could be negative, as long as the net balance of the two accounts remained non-negative. By borrowing in one account and depositing an equal amount in the other, the taxpayer would be able to decelerate or accelerate lifetime cash flows to ensure adequate lifetime averaging. But, because the two accounts would impose the same effective tax rates under successful averaging, there would be no scope for arbitrage beyond that used to accomplish the averaging. ${ }^{8}$

One subtle point to recognize about this approach to averaging (whether under the Blueprints cash-flow tax or the generalized version) is that it would not generally leave the investor in a situation in which the risk-adjusted before-tax return to investment equals the interest rate, i.e., $V\left(r_{s}\right)=i$. Even with averaging, future tax rates would still be uncertain. As a consequence, the taxpayer's portfolio decisions would depend not simply on the expected tax rate, but also on the covariance between the tax rate and each asset's before-tax returns. For example, an asset offering higher returns when the tax rate is higher (as would be the case if higher than expected asset returns are associated with a higher standard of living) would serve as a hedge against tax rate variation, leading the investor to accept a lower before-tax return than if the asset's before-tax returns were independent of tax rate variation. This incentive to offset tax-

\footnotetext{
${ }^{8}$ It is possible some form of explicit averaging could be used instead of the self-averaging system envisioned here. Typical averaging mechanisms, however, bring with them, at least in some degree, the sort of intertemporal tax rate variation, and hence intertemporal distortions, that the GCFT system is designed to avoid.
} 
rate risk might seem a source of inefficiency, distorting taxpayer behavior in response to individual risks that are socially diversifiable. But risks that could be diversified need to be taken into account if no mechanism actually exists for diversification. Once tax-rate risk has been introduced, it is privately and socially optimal for taxpayers to offset the risk unless there is some other mechanism that allows them to do so, i.e., to pool tax-rate risk with other taxpayers.

\section{Changing the tax parameters as a matter of changing policy}

One of the under-appreciated features of a proper accrual tax on capital income is that time-variation in the rate of a tax has no allocative effects, apart from whatever follows from variation in after-tax rates of return. So, for example, with mark-to-market accounting (if it were feasible), variation in tax rates, whether anticipated or not, would have no consequences for asset prices, including the relative prices of assets of different durability or different vintages. ${ }^{9}$ As we have already discussed, this is not the case for cash-flow taxes. In the classic cash-flow implementation of a consumption tax, for example, the constancy of the rate through time is critical for all of the consumption-type properties of the system. In the generalized cash-flow tax, we have used a carefully articulated intertemporal variation in the tax rate to produce the equivalence of an accrual income tax. Any dependence of the generalized cash-flow tax rate on time must be appropriately coordinated with changes in the capital income tax rate in a way anticipated by the investors in the system for it to work.

In the conventional income tax, a single rate applies to both capital and labor income. In the generalized cash-flow tax, the taxation of capital income is implicit, and at a rate that typically bears no resemblance to the current rate of tax on cash flows. We have discussed above the possibilities for varying the implicit rate of capital income tax, $t$, via the slope of the tax

\footnotetext{
${ }^{9}$ A concise presentation of this result may be found in Samuelson (1964).
} 
function's trajectory over time. Greater challenges are presented by the, arguably more common, policy objective of varying the overall level of cash flow tax rates, as determined by the gain tax rate, $g$. The problem is well illustrated by the case of the standard cash-flow tax, with its implicit capital income tax rate of zero. Changing the rate of a universal cash-flow tax from 25 percent to 30 percent from one period to the next, for example, implies a huge penalty on saving undertaken before the change. And if the system offers the opportunity to save outside the cashflow tax system, on what Blueprints called a "tax prepaid basis," huge arbitrage pressures (to lend on a deductible, cash-flow basis and borrow on a tax prepaid basis) are implied.

Exactly analogous problems are presented by the generalized cash-flow tax. The twoaccount system developed for the Blueprints cash-flow tax, already discussed above in the context of lifetime progressivity, was also envisioned as a device for dealing with tax rate changes under the cash-flow tax. This same two-account approach, utilizing the Tax Anticipation Account, could also serve under the generalized cash-flow tax to preserve the flexibility to change tax schedules through time as a matter of policy, while retaining the consistent income tax treatment of capital that is the raison d'etre of the system.

It is well known that transition from an ideal or actual income tax to a consumption-type tax raises significant issues, both of incentive effects and of incidence. Similar issues would be raised for a transition to the generalized cash-flow tax regime. As in the income-to-consumption tax context, many, if not all of those issues are raised generically by the process of policy-chosen variation in tax rates. Possible solutions might be sought in the same place.

\section{Conclusion}

We have shown in this paper the unique form that must be taken by a tax system based entirely on realization accounting to implement a uniform capital income tax, or, equivalently, a 
uniform wealth tax. We have also shown how such a tax can be supplemented with an optional accounting for a segregated subset of actively traded securities, subjected separately to mark-tomarket taxation at the uniform capital income tax rate, to permit a fully graduated tax system applicable to labor income.

One may view this paper's contribution as extending the relationship between the standard cash-flow tax and a zero accrual tax on capital income. As in this previously analyzed case, the effective tax burden on marginal capital income is the same under the alternative tax regimes - the generalized cash-flow tax and the accrual tax - but the timing of tax collections and the burden on inframarginal rents differ.

Our presentation has eschewed a rehearsal of the familiar arguments whether a system that taxes capital income should be regarded as desirable policy option. In a sense, though, it may help narrow the terms of the debate, for it illustrates that one may determine separately whether to implement cash-flow taxation and whether to impose a marginal tax rate on capital income. This narrowing of the debate casts an interesting light on the question of whether capital income taxes are desirable. On the one hand, implementation of a system of uniform capital income taxation is more feasible than was thought. On the other hand, the imposition of a positive capital income tax rate, conditional on having adopted the generalized cash-flow tax, seems all the more arbitrary. 


\section{References}

Auerbach, Alan J., "Retrospective Capital Gains Taxation," American Economic Review, March $1991,81,167-178$.

Bradford, David F., "Fixing Realization Accounting: Symmetry, Consistency and Correctness in the Taxation of Financial Instruments," Tax Law Review, Summer 1995 (issued 1997), $50,731-785$.

Bradford, David F., and the U.S. Treasury Tax Policy Staff, Blueprints for Basic Tax Reform, $2^{\text {nd }}$ ed., Washington, DC: Tax Analysts, 1984 (1 ${ }^{\text {st }}$ ed. published, U.S. Treasury, 1977).

Gordon, Roger H., “Taxation of Corporate Capital Income: Tax Revenues Versus Tax Distortions," Quarterly Journal of Economics, February 1985, 100, 1-27.

Kaplow, Louis, “Taxation and Risk Taking: A General Equilibrium Perspective," National Tax Journal, 47, December 1994, 789-798.

Kaplow, Louis, “On the Divergence Between 'Ideal' and Conventional Income-Tax Treatment of Human Capital," American Economic Review, 86, May 1996, 347-352.

Konrad, Kai A., "Risk Taking and Taxation in Complete Capital Markets," The Geneva Papers on Risk and Insurance, 16, December 1991, 167-177.

Nielsen, Soren Bo, and Peter Birch Sørensen, “On the Optimality of the Nordic System of Dual Income Taxation,” Journal of Public Economics, February 1997, 63, 311-29.

Samuelson, Paul A., 1964, “Tax Deductibility of Economic Depreciation to Insure Invariant Valuations, Journal of Political Economy, June 1964, 72, 604-06.

Sandmo, Agnar, "The Effects of Taxation on Savings and Risk Taking," in A. Auerbach and M. Feldstein, eds., Handbook of Public Economics, vol. 1, Amsterdam: North-Holland, $1985,265-311$.

Vickrey, William, “Averaging of Income for Income Tax Purposes,” Journal of Political Economy, June 1939, 47, 379-97.

Warren, Alvin C., Jr., "Financial Contract Innovation and Income Tax Policy, " Harvard Law Review, December 1993, 107, 460-492. 


\section{Appendix A. Basic Propositions}

This appendix proves several propositions referred to in the text. These propositions and their proofs follow those in Auerbach (1991) for the more general tax scheme discussed here, of which Auerbach's is a special case.

Proposition 1: Condition (2) in the text is necessary and sufficient for the achievement of holding-period neutrality for the class of assets with no intermediate distributions.

proof: At any date $s$, the net value of an asset to the investor is the value of the asset less the accumulated tax liability. To continue to hold the asset for another period, the investor requires a certainty-equivalent return equal to the after-tax interest rate $i(1-t)$. Thus, in equilibrium,

$$
V\left(A_{s+1}-T_{s+1}\right)=\left(A_{s}-T_{s}\right)(1+i(1-t))
$$

Combined with equation (2), (A1) implies that $V\left(A_{s+1}\right)=(1+i) A_{s}$, regardless of $A_{s}$ or $s$. Hence, (2) implies holding-period neutrality. Combined with the requirement that $V\left(A_{s+1}\right)=(1+i) A_{s}$ for holding-period neutrality, (A1) implies (2).

Proposition 2: For an asset with no intermediate distributions, a tax on realization of the form:

$$
T_{s}=\left[1-(1-g)\left(\frac{1+i(1-t)}{1+i}\right)^{s-D}\right] A_{s}
$$

is the only one based on the information set $\left(t, i, s, A_{s}\right)$ that satisfies the condition for holdingperiod neutrality, given as expression (2) in the text.

proof: Consider a tax rule based on the admissible information set: 


$$
T_{s}=F\left(t, i, s, A_{s}\right) .
$$

Since the division of assets is arbitrary, there must exist some function $f(\cdot)$ such that

$$
F\left(t, i, s, A_{s}\right)=f(i, t, s) A_{s} .
$$

Using (A4), we may express the tax at date $s+1$ as:

$$
T_{s+1}=f(i, t, s+1) A_{s+1}=f(i, t, s+1)\left(1+r_{s}\right) A_{s}
$$

If $F(\cdot)$ is holding-period neutral, then it will be true that $V\left(r_{s}\right)=i$, so (A5) implies that

$$
V\left(T_{s+1}\right)=f(i, t, s+1)(1+i) A_{s}
$$

By expression (2) in the text, which is assumed to hold, we also have:

$$
V\left(T_{s+1}\right)=[1+i(1-t)] T_{s}+t i A_{s}=[1+i(1-t)] f(t, i, s) A_{s}+t i A_{s}
$$

Combination of expressions (A6) and (A7) produces the first-order difference equation,

$$
f(t, i, s+1)(1+i)=(1+i(1-t)) f(t, i, s)+t i
$$

for which the general solution is:

$$
f(t, i, s)=\left[1-\left(\frac{1+i(1-t)}{1+i}\right)^{s}\right]+\left(\frac{1+i(1-t)}{1+i}\right)^{s} f(t, i, 0)
$$


For $f(t, i, 0)=0,(\mathrm{~A} 9)$ yields the discrete-time version of the system in Auerbach (1991). For $f(t, i, 0)=\left[1-(1-g)\left(\frac{1+i(1-t)}{1+i}\right)^{-D}\right]$, the result in (A2) obtains. Because the choices of $g$ and $D$ are arbitrary and can be set to produce any value of $f(t, i, 0)$, the system in (A2) is unique. Indeed, there are an infinite number of ways to impose the same tax system by varying the parameters $g$ and $D$ at the same time, holding $(1-g)\left(\frac{1+i(1-t)}{1+i}\right)^{-D}$ constant.

Proposition 3: For an asset with intermediate tax payments, $\tau_{s}$, and intermediate distributions, $d_{s}$, the following condition is necessary and sufficient for a tax to be holding-period neutral:

$$
V\left(T_{s+1}\right)=[1+i(1-t)] T_{s}+t i A_{s}-\tau_{s}
$$

proof: We follow the proof to Proposition 1 above. In portfolio equilibrium it must be true that

$$
V\left(A_{s+1}-T_{s+1}\right)+d_{s}-\tau_{s}=\left(A_{s}-T_{s}\right)(1+i(1-t))
$$

Combined with equation (A10), (A11) implies that $V\left(A_{s+1}\right)=(1+i) A_{s}$, regardless of $A_{s}$ or $s$. Hence, (A10) implies holding-period neutrality. Combined with the requirement that $V\left(A_{s+1}\right)=(1+i) A_{s}$ for holding-period neutrality, (A11) implies (A10).

Proposition 4: For an asset with intermediate distributions at the end of period $s, d_{s}$, a tax regime that taxes the final distribution according to (A2) and all intermediate distributions according to:

$$
\tau_{s}=\left[1-(1-g)\left(\frac{1+i(1-t)}{1+i}\right)^{s+1-D}\right] d_{s}
$$


satisfies condition (A10) and hence is holding-period neutral.

proof: Under the assumed tax system, the tax due on the asset's final realization if it occurs at date $s+1$ is

$$
T_{s+1}=\left[1-(1-g)\left(\frac{1+i(1-t)}{1+i}\right)^{s+1-D}\right] A_{s+1}
$$

which, after some algebra, may be rewritten (using the analogous definition of $T_{s}$ ) as:

$$
\begin{aligned}
& T_{s+1}=[1+i(1-t)] T_{s}+t i A_{s}+\left[1-(1-g)\left(\frac{1+i(1-t)}{1+i}\right)^{s+1-D}\right]\left(r_{s}-i\right) A_{s} \\
& =[1+i(1-t)] T_{s}+t i A_{s}+\left[1-(1-g)\left(\frac{1+i(1-t)}{1+i}\right)^{s+1-D}\right]\left(r_{s} A_{s}+d_{s}-i A_{s}\right)-\tau_{s}
\end{aligned}
$$

(A14)

where the second line of (A14) uses expression (A12) to substitute for $d_{s}$. However, for a tax system that is holding-period neutral, it will turn out that the certainty-equivalent value of the before-tax return equals the interest rate, e.g., $V\left(r_{s} A_{s}+d_{s}\right)=i A_{s}$. Substituting this into (A14), after applying $V(\cdot)$ to both sides, yields expression (A10).

\section{Appendix B. Intertemporal Optimization and Leisure}

This appendix demonstrates the proposition stated in the text, that including labor income under the generalized cash-flow tax eliminates the intertemporal leisure distortion.

We start with the optimization problem of a household facing uncertain asset returns. At time $v$, the household seeks to maximize the expected utility of lifetime consumption $(c)$ and leisure ( $($ ) through the last period of life, $T$, 


$$
E_{v}\left(\sum_{s=v}^{T} U_{s}\left(c_{s}, l_{s}\right)\right)
$$

where $E_{v}(\cdot)$ is the expectation based on the information set at time $v$. The household's budget constraint may be expressed in terms of the evolution of the amount of wealth it has available for consumption each period, say $W_{s}$. At date $s$, this equals the value of the household's risky $\left(A_{s}\right)$ and safe $\left(B_{s}\right)$ assets less the tax that would have to be paid in selling these assets, or $W_{s}=$ $\left(A_{s}+B_{s}\right)\left(1-\theta_{s}\right)$, where $\theta_{s}=\left[1-(1-g)\left(\frac{1+i(1-t)}{1+i}\right)^{s-D}\right]$ is the tax rate at date $s$. The amount available after waiting a period takes into account asset returns, the change in the tax rate, and after-tax labor earnings net of consumption (which we assume occur at the end of the period), or

$$
W_{s+1}=\left[A_{s}\left(1+r_{s}\right)+B_{s}(1+i)\right]\left(1-\theta_{s+1}\right)+w\left(1-l_{s}\right)\left(1-\theta_{s+1}\right)-c_{s}
$$

where a unit labor endowment is assumed and $w$ is the wage rate, assumed for simplicity to be constant over time. Using the definitions of $W$ and $\theta$, we may rewrite (B2) as:

$$
W_{s+1}=[1+i(1-t)] W_{s}+\left(r_{s}-i\right) A_{s}\left(1-\theta_{s+1}\right)+w\left(1-l_{s}\right)\left(1-\theta_{s+1}\right)-c_{s} .
$$

The household's problem consists of maximizing the expression in (B1) subject to (B3) and to the condition that terminal wealth be non-negative. Expressing this problem using Bellman's equation, we have:

$$
V_{s}\left(W_{s}\right)=\max _{c_{s}, l_{s}, A_{s}}\left\{U_{s}\left(c_{s}, l_{s}\right)+E_{s} V_{s+1}\left(W_{s+1}\right)\right\}
$$

where the state variable $W_{s+1}$ is determined by (B3). 
Based on (B4), the first-order conditions with respect to $A_{s}, c_{s}, l_{s}$, and $W_{s}$ may be written:

(B5a)

(B5c)

$$
U_{s c}=E_{s}\left(V_{s+1}^{\prime}\right)
$$

$$
\begin{aligned}
& U_{s l}=E_{s}\left(V_{s+1}^{\prime}\right) w\left(1-\theta_{s+1}\right) \\
& V_{s}^{\prime}=E_{s}\left(V_{s+1}^{\prime}\right)[1+i(1-t)]
\end{aligned}
$$

where $U_{s c}=\partial U_{s} / \partial c_{s}$ and $U_{s l}=\partial U_{s} / \partial l_{s}$ are the marginal utilities of consumption and leisure at date $s$, and $V_{s}^{\prime}$ is the marginal value of wealth at date $s$. For simplicity, we have assumed that future tax rates are known and that future wage and interest rates are constant.

Expression (B5a) is the condition that the marginal utility of consumption equals the marginal value of wealth, and (B5b) is the analogous condition for leisure. Expression (B5c) is simply the condition, proved above, that the valuation of the risky asset's return be the risk-free rate. Expression (B5d) says that the marginal value of wealth is expected to fall over time at the after-tax interest rate, $i(1-t)$. Substituting this expression into (B5a) for successive periods gives the standard result that the marginal utility of consumption is expected to fall over time at the after-tax interest rate. Following the same procedure for labor using (B5b) and (B5d) yields:

$$
E_{s}\left(U_{s+1 l}\right)=E_{s}\left[E_{s+1}\left(V_{s+2}^{\prime}\right) w\left(1-\theta_{s+2}\right)\right]=E_{s}\left(V_{s+2}^{\prime}\right) w\left(1-\theta_{s+2}\right)=\frac{E_{s}\left(V_{s+1}^{\prime}\right)}{1+i(1-t)} w\left(1-\theta_{s+2}\right)
$$

$$
=\frac{U_{s l}\left(1-\theta_{s+2}\right)}{(1+i(1-t))\left(1-\theta_{s+1}\right)}=\frac{U_{s l}}{1+i}
$$

That is, the household's intertemporal marginal rate of substitution for leisure is based on the before-tax interest rate, as would be true in the absence of taxation. It is clear from the second line of (B6) that this result hinges on labor's tax rate changing over time. Were the tax on labor income fixed, the resulting marginal rate of substitution would be based on $i(1-t)$ rather than $i$. 